\title{
MODEL-BASED LEARNING: AN INQUIRY APPROACH TO TEACH SCIENCE
}

\author{
Tiago Ribeiro ${ }^{1}$, Dulce Lima ${ }^{1}$, Rosely Imbernon ${ }^{2}$, Conceição Pereira ${ }^{3}$, \& Clara Vasconcelos ${ }^{1}$ \\ ${ }^{I}$ Science Teaching Unit and Earth Science Institute, Faculty of Sciences of the University of Porto \\ (Portugal) \\ ${ }^{2}$ School of Arts, Sciences and Humanities of the University of São Paulo (Brazil) \\ ${ }^{3}$ School of Education of the Polytechnic Institute of Lisbon (Portugal)
}

\begin{abstract}
Mountain building was one of the first geological phenomena simulated through modeling in the early nineteenth century. Several scientific models were created by geologists in an attempt to understand deformation structures such as faults and folds. However, the learning of this scientific content requires a high level of abstraction and the recall of previous knowledge. The difficulties finding in teaching and learning this process makes evident the not surprising huge alternative concepts diagnose in students. The modeling of mountain building can facilitate the learning process, the irradiation of alternative conceptions and the mobilization of the new learning to solve problems of daily life. With the intention to teach mountain building processes in $7^{\text {th }}$ grade (students age ranging 12-13 years) the authors came across with the need to verify if an inquiry model-based approach could promote meaningful learning in science students. The purpose of this study was not only finding results to this research problem through model-based learning, but also developing education resources to evaluate if the learning was meaningful. Researchers adopt a mixed-methods research (QUAN-qual model) with the data analyzed based on statistics procedure. The data triangulation was made with focus group interviews. A two hours' intervention program was implemented in a science class composed by thirty students $(n=30)$ of a school in the north of Portugal. Before the intervention students were asked to answer a diagnostic test. After intervention students filled a Gowin's Vee. Six focus group (five students per group) were established and interviews were conducted by a member of the research team. Results showed that girls had better achievement in the diagnostic test in questions related to the identification of faults and folds $\left(\chi_{4}^{2}=10.874\right.$; $\mathrm{p}=0.028)$, in the correspondence between the types of forces that originate these structures $\left(\chi^{2}{ }_{8}=16.148\right.$; $\mathrm{p}=0.040)$ and their respective deformation regimes $\left(\chi^{2}{ }_{1}=9.357 ; \mathrm{p}=0.002\right)$. Likewise, female students had a better performance in completing Gowin's Vee $(\rho=0.515$; $p=0.004)$. Nevertheless, both boys and girls explained in the focus interviews how they achieved a meaningful learning supported in the inquiry models' activities.
\end{abstract}

Keywords: Inquiry, models, meaningful learning, mixed method research, natural sciences.

\section{Introduction}

The most recent reforms in Science Education have placed emphasis on Inquiry-Based Teaching (IBT) (Gilbert \& Justi, 2016; Kawalkar \& Vijapurkar, 2015). However, these guidelines haven't been fully implemented in Portuguese schools, perhaps on account of the challenge that adopting these practices represents, and because there is a significant distrust in their contribution for the improvement of teaching. However, studies have demonstrated the potential of these practices (Kawalkar \& Vijapurkar, 2015). The IBT belongs to a Socio-constructivist dimension of learning and aims to contribute to the personal and social development of students, encouraging them to critically participate in today's society. In IBT, the teacher is a learning facilitator that not only conveys conceptual knowledge but also assists students in finding solutions, through observation, questioning and argumentation (Kawalkar \& Vijapurkar, 2015; Fonseca, Barreiras \& Vasconcelos, 2005). There are several strategies to develop a teaching process that will match these guidelines. One of them is laboratory work.

Accordingly, several authors argue in favor of laboratory practices in the Natural Sciences classroom (Kim \& Tan, 2011; Leite, 2000; Torres \& Vasconcelos, 2015; Vasconcelos \& Torres, 2017). Lab work is considered to be an enhancer of competencies, attitudes and values that favor students' 
motivation, the learning of scientific methodology and the development of scientific attitudes (Leite, 2000). When it comes to teaching Natural Sciences, working with models seem to be beneficial. The models in Natural Sciences classes helps the learning process and promotes a better understanding of scientific concepts, increasing the students' engagement, and improving their knowledge, which, together, may reduce the lack of interest in the curricula (Spronken-Smith, 2012). According to IBT and since models are central to scientific activity, students should seek to mirror the scientific activity, which would allow them to experience the process of knowledge building (Bolacha, Martins, Barros, Deus, \& Fonseca, 2009).

The mountain building was one of the first geological phenomena simulated by modeling. However, learning this scientific content requires a high level of abstraction and the use of significant prior-knowledge, which may explain the existence of alternative conceptions. Modeling mountain building may facilitate this learning process and help to build knowledge that is fundamental to the understanding of Earth and Science (Bolacha et al., 2009; Moutinho, Moura \& Vasconcelos, 2016).

\section{Methodology}

This research was based on a mixed-based methodology (QUAN-qual model). Its development sought to evaluate the impact of the use of modeling in Natural Sciences class of the $7^{\text {th }}$ grade. The model aimed to favor the learning process of orogenic phenomena and the understanding of the presence of marine fossils in the Himalayas. The model activity was performed as an inquiry approach leading students to observe, register data, analyze and conclude. To register their inquiry activities students were asked to fill a Gowin's Vee.

\subsection{Sample, instruments and procedure}

The study was carried out in a school in the city of Oporto (Portugal); it was applied to a $7^{\text {th }}$ grade Natural Sciences classroom (figure 1), with 30 students, aged 12 to 13 years; the majority of participants were female $(n=19 ; 63.3 \%)$.

Figure 1. Photographic record of the intervention program.
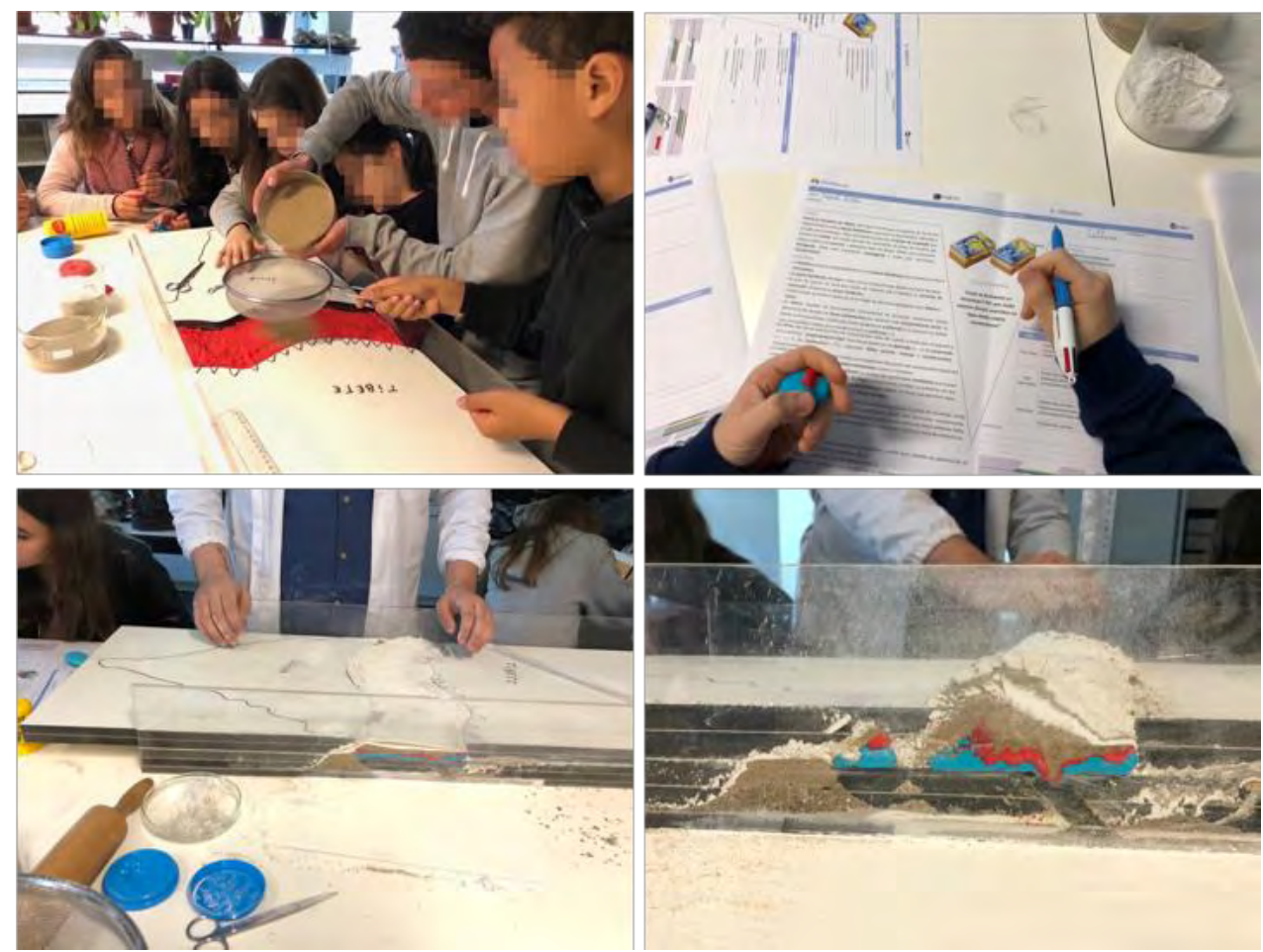

The instruments chosen for data collection were the cognitive test, Gowin's Vee, and an interview guide (figure 2). A cognitive test was used, allowing the identification of the conceptions of the participants. Gowin's Vee comprised two central questions - "How were the Himalayas formed? Why are there marine fossils at the top of this mountain?" - students were asked to answer these questions through modeling activity. A structured interview was also used, based on an interview script.

Data collection took place at three different times. Firstly, a cognitive test was applied. Afterwards, data was collected during the modeling activity by filling Gowin's Vee. From a learning perspective, the 
Gowin's Vee helps students, especially the younger ones, to recognize the complexity of the process of knowledge construction. This instrument allows the contact between the new conceptual content (to be learned) and the concepts that the student already had, enabling the restructuring and construction of knowledge. Additionally, this tool facilitates the identification of the various scientific concepts related to a certain theme and its relations, systematizing them in a condensed and clear way (Gowin \& Alvarez, 2005). In addition to its value in the learning process, the analysis of this type of register allows us to investigate how students organize and integrate scientific knowledge and procedures, as well as an important data collection instrument able to be used in educational research (Gowin \& Alvarez, 2005).

Finally, several interviews took place within six focus groups (five students each). In this variety of interviews, the researcher seeks to understand the mutual understanding of the individuals, as well as their personal visions. Focus groups are especially helpful when the interaction between respondents leads to a shared understanding of the questions posed by the researcher (Gay, Mills \& Airasian, 2012). The groups were defined by the researchers in order to guarantee intergroup homogeneity and intragroup heterogeneity.

Figure 2. Different stages of the intervention program.

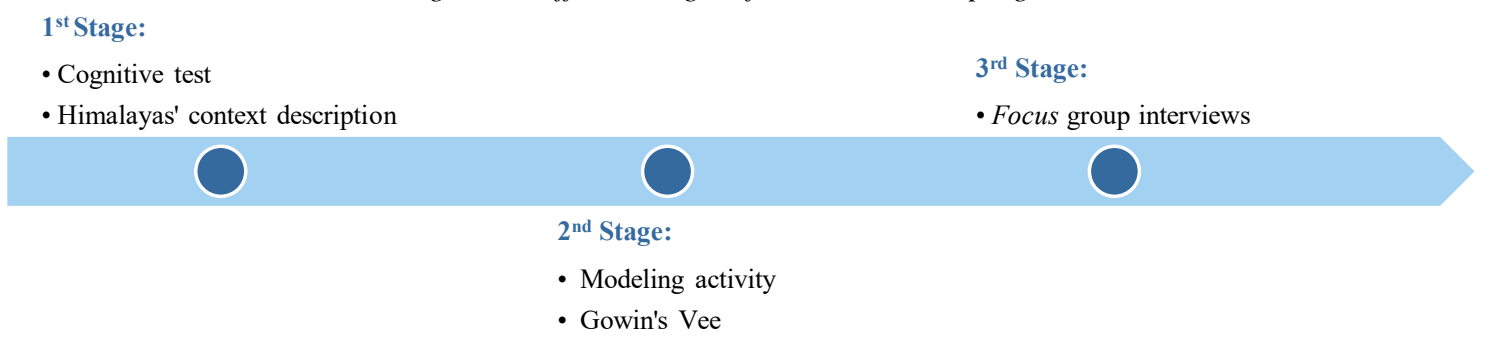

Data was analyzed by resorting to statistical methods and content analysis, which provided the framework for the organization and description of results.

\section{Results}

\subsection{Cognitive test}

Results were satisfactory, with an average of $60.5 \%$. However, 8 students $(26.6 \%)$ scored less than $50 \%$. The majority of students associate brittle and ductile deformation to the formation of failures $(70.0 \%)$ and folds $(73.3 \%)$. Nonetheless, they showed difficulties in identifying these structures when looking at a schematic drawing; only 14 students (46.7\%) managed to identify the structures, and only 1 student $(3.3 \%)$ associated the structures to the type of force involved. Ten students $(33.3 \%)$ correctly ordered the statements about the sequence of events that give rise to a failure.

When asked why there are marine fossils at the top of the Himalayas, no student was able to answer $(0.0 \%)$. Nine students $(30.0 \%)$ related this fact to the action of convergent forces/movements but failed to fully explain the phenomenon. Three students (10.0\%) pointed out changes of sea level as an explanation and two other students $(6.7 \%)$ said that the mountain "was born from the seabed".

Statistical analysis was performed using chi-square independence test. Significant differences were found in relation to the frequency of correct answers and gender, in the questions related to the identification of faults and folds $\left(\chi^{2}{ }_{4}=10.874 ; \mathrm{p}=0.028\right)$ and in corresponding the nature of forces to the origin of these structures $\left(\chi^{2}{ }_{8}=16.148 ; \mathrm{p}=0.040\right)$. The recognition of the brittle $\left(\chi_{1}^{2}=9.357 ; \mathrm{p}=0.002\right)$ and ductile $\left(\chi_{1}^{2}=9.357 ; p=0.009\right)$ regimens showed significant differences.

The majority of correct answers were found in the girls. The better results found in girls may be explained by an earlier psychological development, which may relate to higher motivation, engagement and attention during classes (Voyer \& Voyer, 2014).

\subsection{Gowin's Vee}

Students made Gowin's Vee as a way to report the modelling inquiry work. Figure 3 shows one of students Gowin's Vee.

After analyzing the Gowin's Vee, results were considered good. The average obtained was 75.2\%, which represented an increase of $14.7 \%$ in relation to the cognitive test. Spearman's coefficient was used to test the correlation between the scores of each instrument and a significant correlation was obtained $(\rho=0.515 ; p=0.004)$. This suggests a positive correlation between conceptual knowledge and its systematization, by filling Gowin's Vee; those participants with best test results were the ones that better completed Gowin's Vee. 
Figure 3. Gowin's Vee as a way to report the modelling inquiry work.

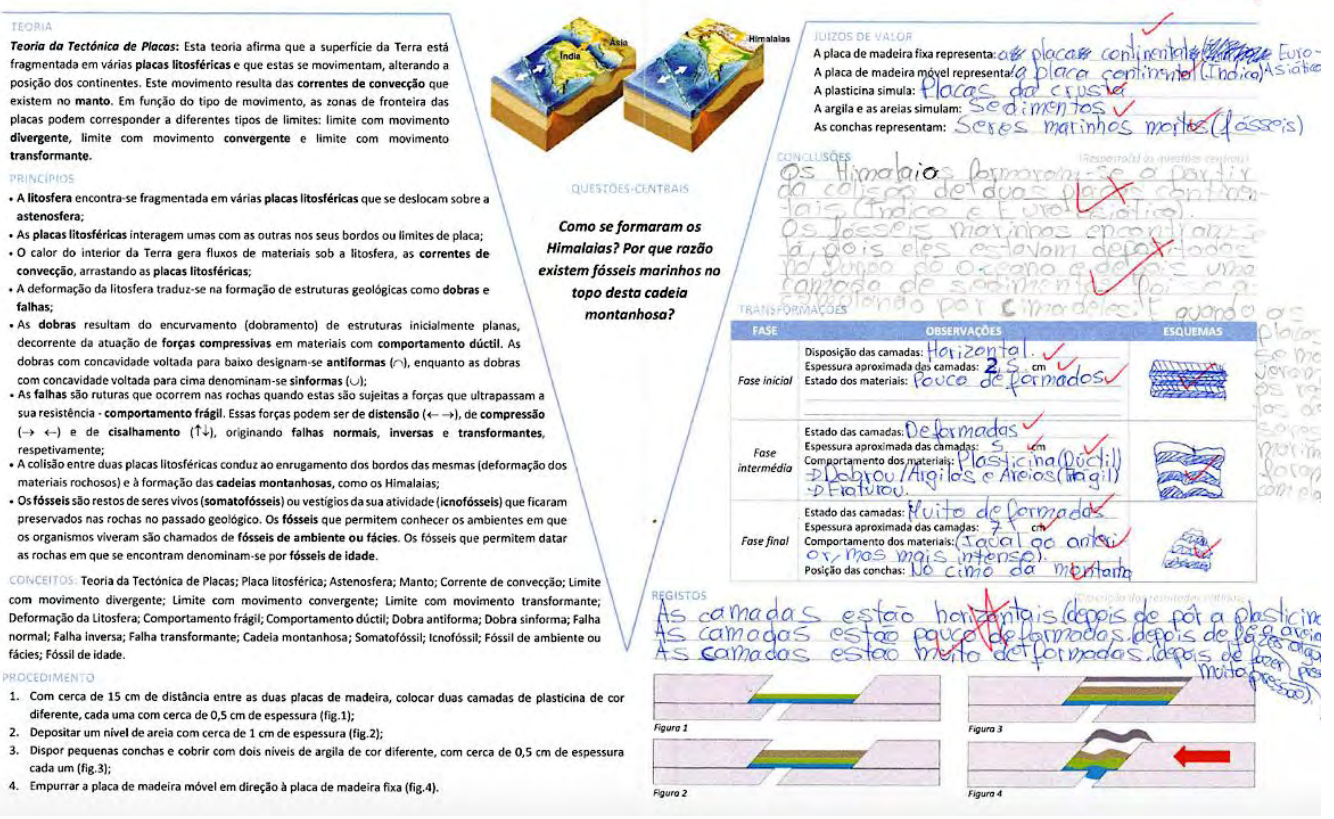

Similarly, to the cognitive test, answers to Gowin's Vee were analyzed using the chi-square independence test. Significant differences were found in relation to the frequency of correct answers and gender, in terms of record-keeping $\left(\chi^{2}=10.318 ; \mathrm{p}=0.035\right)$ and value judgments linked to the representation of a fixed plate $\left(\chi_{1}^{2}=7.177 ; \mathrm{p}=0.007\right)$. Again, the best results were obtained by females, which may be similarly explained.

\subsection{Focus group interviews}

Performance in focal interviews was very good. Five of the six groups were able to correctly define a fault and every student was able to clarify what a fold was. In both cases, these geological formations were related to the typology of the forces at hand and their corresponding deformation regimens. Students were able to explain the mountain building, by stating: "the rocks, due to the compressive forces of the lithospheric plates, deform and rise, since they become thicker"(II-1). One student pointed out that the deformation of the lithosphere and the formation of mountains results from the fact that the interior of the Earth is "...always in motion due to the convection currents"(V-1).

Additionally, all groups recognized the lithospheric plates that were involved in the formation of the Himalayas and their nature. In relation of the existence of marine fossils at the top of the Himalayas, five groups reported that they made it possible to determine the environment in which the rocks were formed, thus stating that "the rocks at the top of the Himalayas were formed at the bottom of the ocean" (I-2). Note that one of the groups reported that these fossils were also important for geochronology.

Results related to the teaching methodology showed that all groups considered that it contributed to the improvement of their learning, by helping them to formulate explanations. Students described this methodology as "more interactive"(I-3) than traditional practices, arguing that "it is easier [to understand] when you see things happening rather than when the teacher is only talking..."(I-1). According to one student, "in the test (...) it reminds us of what we did in the class and helps us to build answers"(II-1), favoring the application of knowledge to new situations.

In relation to learning, one student emphasized that: "with models we can ask more questions because the topic is not so abstract. We can ask questions such as 'Why did this happen?'"(III-2), which shows an important potential of this methodology in terms of questioning and formulating hypotheses. In addition, students suggest that the model is a way of "seeing how nature works"(III-3), bringing real world phenomena to the curricular contents.

\section{Conclusions}

Inquiry activity using modeling proved to have a positive impact in learning contents related to the scientific theme at hand. The teaching methodology that was employed favored the emergence of significant learning, which were reflected in improved results, in between the cognitive test and Gowin's Vee, which were later confirmed through interviews. After this activity, students were able to explain the 
formation of folds and faults, distinguishing between the fragile and ductile behavior. In relation to the formation of mountains, findings showed an improvement in students' mental models, evidenced by the quality of answers and putting aside alternative conceptions. This cognitive development was also notorious in terms of learning about the importance of the presence of marine fossils at the top of the Himalayas in the reconstruction of the Earth's history.

Students applied and developed several competences such as observation, record-keeping, formulating hypothesis, data analysis and processing, and drawing conclusions, which are essential in the completion of the Gowin's Vee and in scientific practice. Students showed an understanding of scientific knowledge, mobilizing it to problem resolution and formulating solutions based on their own observations and inferences, which resulted from the manipulation of the model. Accordingly, authors argue that modeling activities are fundamental to the improvement of scientific education, in its different domains.

\section{References}

Bolacha, E., Martins, M., Barros, M., Deus, H. M., \& Fonseca, P. E. (2009). Modelação Análoga da Formação de Montanhas-Orogenias: um desejável contributo para a Cultura Científica. Actas do XIII Encontro Nacional de Educação em Ciências, Instituto Politécnico de Castelo Branco, 713-722.

Fonseca, P., Barreiras, S., \& Vasconcelos, C. (2005). Trabalho experimental no ensino da Geologia: Aplicações da investigação na sala de aula. Enseñanza de las ciencias, (Extra), 1-5.

Gay, L., Mills, G., \& Airasian, P. (2012). Educational research: Competencies for analysis and applications $\left(10^{\text {th }}\right.$ ed.). New Jersey: Pearson.

Gilbert, J. K., \& Justi, R. (2016). Modelling-based teaching in science education. Switzerland: Springer International Publishing.

Gowin, D. B., \& Alvarez, M. C. (2005). The art of educating with V diagrams. Cambridge: Cambridge University Press.

Kawalkar, A., \& Vijapurkar, J. (2015). Aspects of Teaching and Learning Science: What students' diaries reveal about inquiry and traditional modes. International Journal of Science Education, 37(13), 2113-2146. doi:10.1080/09500693.2015.1067933

Kim, M., \& Tan, A. L. (2011). Rethinking Difficulties of Teaching Inquiry-Based Practical Work: Stories from elementary pre-service teachers. International Journal of Science Education, 33(4), 465-486. doi: 10.1080/09500691003639913

Leite, L. (2000). O trabalho laboratorial e a avaliação das aprendizagens dos alunos. In M. Sequeira et al. (Ed.), Trabalho prático e experimental na educação em ciências. (pp. 91-108). Braga: Universidade do Minho.

Moutinho, S., Moura, R., \& Vasconcelos, C. (2016). Mental models about seismic effects: students' profile based comparative analysis. International Journal of Science and Mathematics Education, 14(3), 391-415. doi:10.1007/s10763-014-9572-7

Spronken-Smith, R. (2012). Experiencing the process of knowledge creation: The nature and use of inquiry-based learning in higher education. Em International Colloquium on Practices for Academic Inquiry. Otago: University of Otago.

Torres, J., \& Vasconcelos, C. (2015). Nature of science and models: Comparing Portuguese prospective teachers' views. Eurasia Journal of Mathematics, Science \& Technology Education, 11(6). doi: 10.12973/eurasia.2015.1407a

Vasconcelos, C. \& Torres, J. (2017). Models in science and for teaching science: Data from an intervention programme. International Journal of Learning and Teaching, 8(5), 308-318.

Voyer, D., \& Voyer, S. D. (2014). Gender differences in scholastic achievement: A meta-analysis. Psychological bulletin, 140(4), 1174. doi:10.1037/a0036620 